\title{
Clinical and Genetic Characteristics of BRCA1/2 Mutation in Korean Ovarian Cancer Patients: A Multicenter Study and Literature Review
}

\author{
Byung Su Kwon, MD, PhD \\ Jung Mi Byun, MD, PhD² \\ Hyun Joo Lee, MD ${ }^{1}$ \\ Dae Hoon Jeong, MD, PhD² \\ Tae Hwa Lee, MD, PhD ${ }^{3}$ \\ Kyung-Hwa Shin, MD, PhD ${ }^{4}$ \\ Dong Soo Suh, MD, PhD' \\ Ki Hyung Kim, MD, PhD'
}

\begin{abstract}
${ }^{1}$ Department of Obstetrics and Gynecology, Biomedical Research Institute, Pusan National University Hospital, Pusan National University School of Medicine, Busan, ${ }^{2}$ Department of Obstetrics and Gynecology, Inje University Busan Paik Hospital, Inje University College of Medicine, Busan, ${ }^{3}$ Department of Obstetrics and Gynecology, Kosin University Gospel Hospital, Kosin University College of Medicine, Busan, ${ }^{4}$ Department of Laboratory Medicine, Pusan National University School of Medicine, Busan, Korea
\end{abstract}

Correspondence: Ki Hyung Kim, MD, PhD Department of Obstetrics and Gynecology, Biomedical Research Institute, Pusan Cancer Center, Pusan National University School of Medicine, 179 Gudeok-ro, Seo-gu, Busan 49241, Korea

Tel: 82-51-990-6226

Fax: 82-51-990-3300

E-mail: ghkim@pusan.ac.kr

Received May 28, 2018

Accepted October 5, 2018

Published Online October 8, 2018

*Byung Su Kwon and Jung Mi Byun contributed equally to this work.

\section{Purpose}

We investigated the clinical relevance and spectrum of BRCA1/2 mutations in Korean ovarian cancer (KoOC) patients.

\section{Materials and Methods}

Two hundred seventy-nine KoOC patients were enrolled from three university hospitals between 2012 and 2017. Their peripheral blood samples were obtained for BRCA1/2 mutation analysis by direct sequencing. Clinicopathological characteristics were retrospectively reviewed, and spectrum analyses of $B R C A 1 / 2$ mutation were assessed by systematic literature review.

\section{Results}

Frequency of BRCA1/2 mutations was $16.5 \%$ in KoOC patients. BRCA1/2 mutations were significantly associated with family history of breast/ovarian cancer $(p<0.001)$, serous histology ( $p=0.044)$, and advanced International Federation of Gynecology and Obstetrics (FIGO) stage (III/IV, $p=0.018$ ) but not with early age-of-onset (age $<50, p=0.729)$. Literature review of $B R C A 1 / 2$ mutations in KoOC patients found 111 (55 distinct) mutations with high proportion of Korean-specific mutations (24/55, 43.6\%). Comparing the spectrum of BRCA1/2 mutation between $\mathrm{KoOC}$ and Korean breast cancer ( $\mathrm{KoBC})$ patients, the ratio of BRCA1-to-BRCA2 mutations was different, with BRCA1 (78.4\%) being predominant in KoOC and BRCA2 in KoBC (59.2\%). The most common mutation also differed between the two (c.3627insA of BRCA1 in KoOC and c.7480C > T of BRCA2 in $\mathrm{KoBC}$ ).

\section{Conclusion}

The clinical relevance of BRCA1/2 mutations in KoOC patients was confirmed but that of early age-of-onset was not. Possible inconsistency in the ratio of BRCA1-to-BRCA2 mutations and the most common mutation between $\mathrm{KoOC}$ and $\mathrm{KoBC}$ may probably suggest presence of mutation sequence-associated penetrance tendency in hereditary Korean breast and ovarian cancer. These data may provide insights for optimal genetic counseling and prophylactic treatment for at-risk relatives of KoOC patients.

\section{Key words}

BRCA1 genes, BRCA2 genes, Germ-line mutation, Koreans, Ovarian neoplasms 


\section{Introduction}

Epithelial ovarian cancer (EOC) is the leading cause of cancer-related deaths in women worldwide and remains the most lethal gynecological cancer [1]. Although the incidence of EOC has traditionally been lower in Korea than in western countries, including the United States and United Kingdom, it has steadily increased over the last few decades because of lifestyle and environmental changes [2]. In 1999, the agestandardized rates for annual EOC incidence and mortality in Korea were 5.0 and 1.7 per 100,000 women-years, respectively, which significantly increased to 6.4 and 2.3 per 100,000 women-years, respectively, by 2014 (both, p < 0.05) [3]. Such increases represent a significant challenge to overcome, and methods for controlling the increasing rates of this cancer are urgently needed.

Defects in BRCA1/2 tumor suppressor genes are the most frequently identified genetic changes associated with ovarian cancer. A BRCA1/2 germline mutation is associated with poor prognostic factors, including early-onset cancer, serous histology, and advanced cancer stages [4]. However, in recent years, accumulating evidence has shown that $B R C A 1 / 2$ mutations are associated with improved survival and improved response to not only platinum-based chemotherapy $[5,6]$ but also targeted therapy using poly(ADP-ribose) polymerase inhibitors $[7,8]$.

Although there have been several reports of $B R C A 1 / 2$ mutation analyses in ovarian and breast cancer cases from Asian populations, there is relatively limited data for the Korean ovarian cancer (KoOC) population. Until now, there have been four independent studies on BRCA1/2 mutations in KoOC patients; however, all of these were relatively smallscale, single-center studies with marked inter-study heterogeneity among their results [9-11]. Furthermore, there has been no spectrum study of BRCA1/2 mutations in KoOC patients, such as nation-wide the Korean Hereditary Breast Cancer (KOHBRA) study [12,13]; KOHBRA study included a total of 2,953 breast cancer patients with high risk of hereditary breast and ovarian cancer (HBOC) enrolled from 36 institutions between 2007 and 2013, covering approximately $2.9 \%$ of the total Korean breast cancer $(\mathrm{KoBC})$ patients during the study period. Thus, we performed comprehensive analyses to estimate the prevalence, clinicopathological significance, spectrum, and penetrance of BRCA1/2 mutations in a large cohort of KoOC patients.

\section{Materials and Methods}

\section{Patients}

A total of 279 EOC patients unselected for family history (FH) were enrolled between May 2012 and December 2017 from three investigational sites in Korea: the Pusan National University Hospital, Inje University Paik Hospital, and Kosin University Gospel Hospital (PIKO). Genetic testing of BRCA1/2 genes in all three investigational hospitals was carried out by the Green Cross Company (Yongin, Korea) during the study period. The inclusion criteria for enrollment were primary EOC patients who had undergone staging surgery and had pathologically confirmed with EOC. Clinical and pathological data were collected for all patients: age at diagnosis, EOC grade, lymph node (LN) metastasis, FIGO stage (International Federation of Gynecology and Obstetrics, 2013), and personal history and FH of cancer. Patients with FH were defined as those with primary breast cancer or with first- or second-degree relatives with breast or ovarian cancer. FH of other cancer include all type of hematologic and non-hematologic malignancies.

\section{Direct sequencing}

Genomic DNA was obtained from peripheral blood leukocytes and was extracted using the Promega DNA purification kit (catalog No. LA1620, Madison, WI) according to the manufacturer's instructions. All exon and intron boundaries of BRCA1/2 were analyzed for mutations using a combination of denaturing high-performance liquid chromatography (WAVE DNA Fragment Analysis System, Transgenomic Inc., San Jose, CA) and bi-directional sequencing with a Big Dye Terminator V3.1 Cycle Sequencing Kit (Life Technologies, Carlsbad, CA) and ABI 3500xl (Life Technologies).

\section{Statistical analyses}

The Human Genome Variation Society nomenclature system (http://www.hgvs.org/ mutnomen) was used for describing sequence variations, and the Breast Cancer Information Core (BIC) database (http:// research.nhgri.nih.gov/ projects /bic/Member/index.shtml) was used for evaluating results. Relationships among categorical variables were evaluated using t or chi-square tests. For all analyses, a p-value $<0.05$ was considered statistically significant. Analyses were performed using SPSS ver. 20.0 (IBM Corp., Armonk, NY). 
A
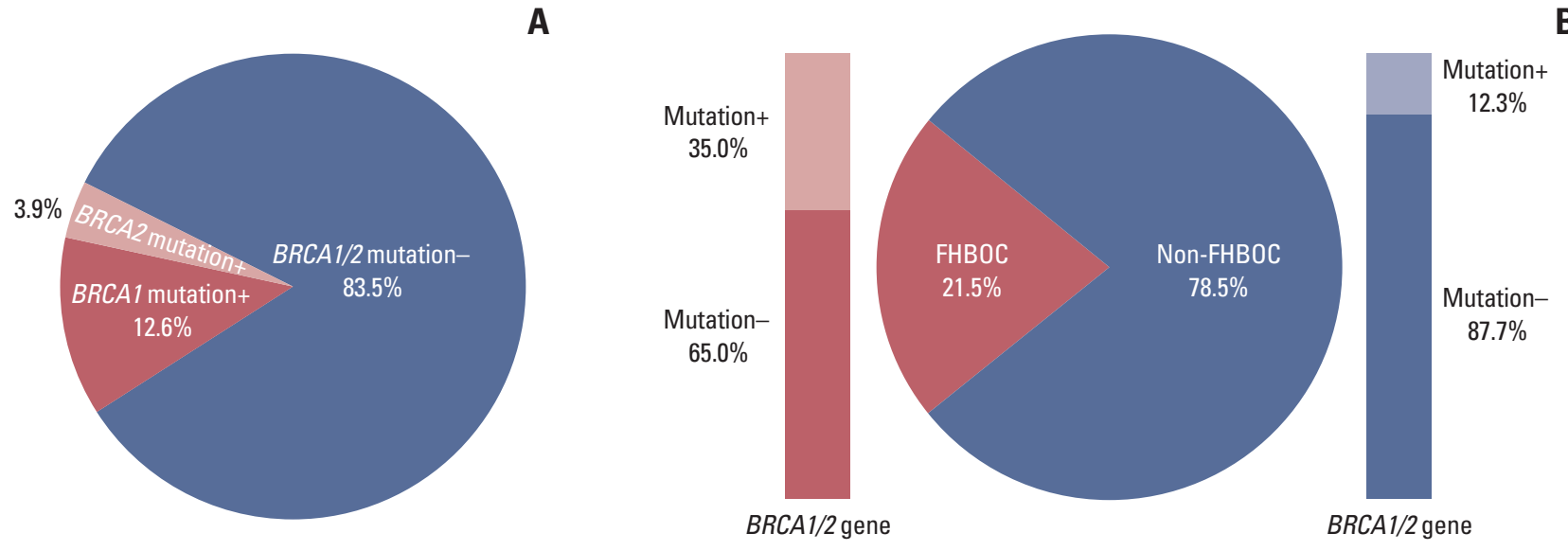

B

Fig. 1. Prevalence of $B R C A 1 / 2$ mutations in unselected 279 Korean ovarian cancer patients. The overall prevalence (A) and prevalence according to family history of breast/ovarian cancer (FHBOC) (B).

Table 1. Association of $B R C A 1 / 2$ mutation status with clinicopathological characteristics in Korean ovarian cancer patients

\begin{tabular}{|c|c|c|c|c|}
\hline Characteristic & Total & $\begin{array}{c}\text { BRCA1/2 } \\
\text { mutation- }\end{array}$ & $\begin{array}{c}\text { BRCA1/2 } \\
\text { mutation+ }\end{array}$ & p-value ${ }^{a)}$ \\
\hline Total & $279(100)$ & $233(83.5)$ & $46(16.5)$ & \\
\hline Age (yr) & $54.15 \pm 10.7$ & $54.2 \pm 10.9$ & $53.7 \pm 9.6$ & 0.765 \\
\hline \multicolumn{5}{|c|}{ Age, early-onset (age < 50) } \\
\hline$<50$ & $93(33.3)$ & $71(30.5)$ & $18(39.1)$ & 0.223 \\
\hline$\geq 50$ & $186(66.7)$ & $162(69.5)$ & $28(60.9)$ & \\
\hline \multicolumn{5}{|l|}{ FHBOC $^{\text {b) }}$} \\
\hline No & $219(78.5)$ & $194(83.3)$ & $25(54.3)$ & $<0.001$ \\
\hline Yes & $60(21.5)$ & $39(16.7)$ & $21(45.7)$ & \\
\hline \multicolumn{5}{|c|}{ FH of other cancers } \\
\hline No & $218(78.1)$ & $190(81.5)$ & $28(60.9)$ & $<0.001$ \\
\hline Yes & $61(21.9)$ & $43(18.5)$ & $18(39.1)$ & \\
\hline \multicolumn{5}{|c|}{ Tumor histology } \\
\hline Serous & $202(72.4)$ & $160(68.7)$ & $42(91.3)$ & 0.002 \\
\hline Non-serous & $77(27.6)$ & $73(31.3)$ & $4(8.7)$ & \\
\hline \multicolumn{5}{|l|}{ FIGO stage } \\
\hline I/II & $96(34.4)$ & $90(38.6)$ & $6(13.0)$ & 0.007 \\
\hline III/IV & $183(65.6)$ & $143(61.4)$ & $40(87.0)$ & \\
\hline \multicolumn{5}{|l|}{ LN metastasis } \\
\hline No & $190(68.1)$ & $166(71.2)$ & $24(51.2)$ & 0.011 \\
\hline Yes & 89 (31.9) & $67(28.8)$ & $22(48.8)$ & \\
\hline
\end{tabular}

Values are presented as number (\%) or mean \pm standard deviation. FHBOC, family history of breast/ ovarian cancer; FH, family history; FIGO, International Federation of Gynecology and Obstetrics; LN, lymph node. a)Continuous variables were analyzed using the Student's t test; categorical variables were analyzed using the chi-square test, ${ }^{b}$ Patients with primary breast cancer or first- or second-degree relatives with breast or ovarian cancer. 


\section{Ethical statement}

This study was approved by the institutional review boards of the abovementioned three institutions. Informed consent was obtained from all participants, and peripheral blood samples were collected from each subject.

\section{Results}

\section{Prevalence of $B R C A 1 / 2$ mutations}

In our direct sequencing analysis of $B R C A 1 / 2$ genes in the 279 unselected EOC patients, pathogenic $B R C A 1$ and $B R C A 2$ mutations were observed in $35(12.6 \%)$ and $11(3.9 \%)$ cases, respectively. The overall prevalence of $B R C A 1 / 2$ mutations in KoOC patients was 16.5\% (Fig. 1A). Among the 279 EOC patients, 60 patients $(21.5 \%)$ had FH of breast or ovarian cancer and $219(78.5 \%)$ did not. The prevalence of BRCA1/2 mutations was higher in the former (21 of $60,35.0 \%$ ) than in the latter (27 of 219, 12.3\%) (Fig. 1B). In specific subgroups according to tumor histology (serous vs. non-serous) and FIGO stage (I/II vs. III/IV), the prevalence of BRCA1/2 mutations was $11.9 \%$ in patients with early stage (I/II) and serous histology, $23.1 \%$ in patients with advanced stage (III/IV) and serous histology, $0 \%$ in patients with early stage (I/II) and non-serous histology and $16.7 \%$ in patients with advanced stage (III/IV) and non-serous histology (S1 Fig.).

\section{Clinical characteristics of $B R C A 1 / 2$ mutations}

Relationships between clinicopathological characteristics and $B R C A 1 / 2$ mutations are listed in Table 1 . The mean ages at the time of onset for patients with and without $B R C A 1 / 2$ mutations were $53.7 \pm 9.6$ years and $54.2 \pm 10.9$ years, respectively, with no significant difference between them $(\mathrm{p}=0.765)$. In addition, we found no significant difference in the proportion of patients with early age-of-onset ( $<50$ years) of ovarian cancers between $B R C A 1 / 2$ mutation carriers and non-carriers ( $39.1 \%$ vs. $30.5 \%, \mathrm{p}=0.223$ ). Patients with $B R C A 1 / 2$ mutations exhibited significantly higher rates of $\mathrm{FH}$ of breast or ovarian cancer $(45.7 \%)$ and other cancers $(39.1 \%)$ compared with those without BRCA1/2 mutations (16.7\% for FH of breast or ovarian cancer; $18.5 \%$ for FH of other cancers; both, $\mathrm{p}<0.001$ ). The occurrence of serous histology was significantly higher in patients with BRCA1/2 mutations $(91.3 \%)$ than in those without $B R C A 1 / 2$ mutations $(68.7 \%, \mathrm{p}=0.002)$. Four patients with $B R C A 1 / 2$ mutations $(8.7 \%)$ were identified as having non-serous histology in this study, with three cases of clear cell-type histology with BRCA1 mutations and one case of endometrioid-type histology with a BRCA2 mutation (S2 Table). In addition, patients with $B R C A 1 / 2$ mutations were more likely to be at an advanced FIGO stage of III/IV (87.0\%) and exhibit LN metastasis $(48.8 \%)$ than those without BRCA1/2 mutations $(61.4 \%, \mathrm{p}=0.007$ for advanced FIGO stage of III/ IV; $28.8 \%, p=0.011$ for LN metastasis) (Table 1). However, multivariate analysis using logistic regression identified $\mathrm{FH}$ of breast/ ovarian cancer $(\mathrm{p}<0.001)$, serous histology $(\mathrm{p}=0.044)$, and advanced FIGO stage (III/IV, $\mathrm{p}=0.018$ ) as the only factors showing independent correlation with BRCA1/2 mutations $(\mathrm{p}<0.05)($ Table 2$)$.

\section{Spectrum of $B R C A 1 / 2$ mutations}

All 46 pathogenic BRCA1/2 mutations detected in this study are listed and summarized in S2 Table. Thirty-two distinct mutations were identified, including 21 in BRCA1 and 11 in $B R C A 2$. For a comprehensive analysis of the $B R C A 1 / 2$ mutation spectrum, all mutations reported in $\mathrm{KoOC}$ patients thus far were investigated and have been summarized in

Table 2. Multivariate logistic regression in Korean ovarian cancer patients between BRCA1/2 mutation status and clinicopathological characteristics

\begin{tabular}{llr} 
Characteristic & \multicolumn{1}{c}{ OR $(95 \%$ CI $)$} & p-value \\
Age $(<50$ yr vs. $\geq 50$ yr) & $1.762(0.861-3.605)$ & 0.121 \\
FHBOC $($ yes vs. no) & $9.089(3.204-25.783)$ & $<0.001$ \\
FH of other cancers (yes vs. no) & $1.223(0.861-2.653)$ & 0.747 \\
Tumor histology (serous vs. non-serous) & $3.834(1.035-14.201)$ & 0.044 \\
FIGO stage (III/IV vs. I/ II) & $3.738(1.258-11.106)$ & 0.018 \\
LN metastasis (yes vs. no) & $1.143(0.538-2.427)$ & 0.729 \\
\hline
\end{tabular}

$\mathrm{OR}$, odds ratio; $\mathrm{CI}$, confidence interval; FHBOC, family history of breast/ ovarian cancer; FH, family history; FIGO, International Federation of Gynecology and Obstetrics; LN, lymph node. ${ }^{a}$ Patients with primary breast cancer or first- or seconddegree relatives with breast or ovarian cancer. 
Table 3. Spectrum of $B R C A 1 / 2$ mutations in Korean ovarian cancer (KoOC) patients

\begin{tabular}{|c|c|c|c|c|c|}
\hline Site & Mutation $^{\text {a) }}$ & Type & $\begin{array}{l}\text { No. of citations } \\
\text { in } \mathrm{KoOC}^{\mathrm{b})}\end{array}$ & $\begin{array}{l}\text { No. of citations } \\
\text { in BIC }\end{array}$ & $\begin{array}{c}\text { No. of citations } \\
\text { in KOHBRA }\end{array}$ \\
\hline \multicolumn{6}{|c|}{ BRCA1 (39 districts) } \\
\hline 2 & c. $1 \mathrm{~A}>\mathrm{G}$ & MS & $1(1)$ & 8 & NR \\
\hline 6 & c.277_279delTTTinsCC & FS & $1(0)$ & 0 & NR \\
\hline 7 & c. $390 \mathrm{C}>\mathrm{A}$ & NS & $8(2)$ & 1 & $\mathrm{R}$ \\
\hline 11 & c.922_924AGCinsT & NS & $5(1)$ & 0 & $\mathrm{R}$ \\
\hline 11 & c. $928 \mathrm{C}>\mathrm{T}$ & NS & $1(0)$ & 0 & $\mathrm{R}$ \\
\hline 11 & c.981_982delAT & FS & $1(1)$ & 13 & $\mathrm{R}$ \\
\hline 11 & c.1179_1180dupAG & FS & $2(2)$ & 0 & NR \\
\hline 11 & c.1716delA & FS & $2(1)$ & 0 & $\mathrm{R}$ \\
\hline 11 & c.1831delC & NS & $2(2)$ & 0 & $\mathrm{R}$ \\
\hline 11 & c.1953delG & FS & $1(1)$ & 0 & NR \\
\hline 11 & c.1962insT & FS & $2(0)$ & 0 & $\mathrm{R}$ \\
\hline 11 & c. 2047delA & FS & $1(0)$ & 0 & NR \\
\hline 11 & c.2359delG & FS & $1(0)$ & 0 & $\mathrm{R}$ \\
\hline 11 & c.2433delC & FS & $4(1)$ & 11 & $\mathrm{R}$ \\
\hline 11 & c. $2914 \mathrm{G}>\mathrm{T}$ & NS & $1(0)$ & 0 & $\mathrm{R}$ \\
\hline 11 & c.3157delG & FS & $1(0)$ & 0 & $\mathrm{R}$ \\
\hline 11 & c.3296delC & FS & $1(0)$ & 2 & $\mathrm{R}$ \\
\hline 11 & c. $.3340 \mathrm{G}>\mathrm{T}$ & NS & $1(0)$ & 1 & $\mathrm{R}$ \\
\hline 11 & c.3377_3378delATinsG & FS & $1(0)$ & 0 & NR \\
\hline 11 & c.3442delG & FS & $5(2)$ & 2 & $\mathrm{R}$ \\
\hline 11 & c. $3607 \mathrm{C}>\mathrm{T}$ & NS & $1(0)$ & 36 & $\mathrm{R}$ \\
\hline 11 & c.3627insA & FS & $14(5)$ & 9 & $\mathrm{R}$ \\
\hline 11 & c. $3895 \mathrm{C}>\mathrm{T}$ & NS & $1(0)$ & 1 & $\mathrm{R}$ \\
\hline 11 & c.3991C $>\mathrm{T}$ & NS & $2(1)$ & 0 & $\mathrm{R}$ \\
\hline 11 & c.4040_4041delGA & FS & $1(0)$ & 0 & NR \\
\hline 11 & c.4041_4042delAG & FS & $2(0)$ & 0 & $\mathrm{R}$ \\
\hline 16 & c. $4801 \mathrm{~A}>\mathrm{T}$ & NS & $1(0)$ & 2 & NR \\
\hline 16 & c. $4981 G>T$ & NS & $1(1)$ & 1 & $\mathrm{R}$ \\
\hline 17 & c.5030_5033delCTAA & FS & $1(1)$ & 17 & $\mathrm{R}$ \\
\hline 18 & c. $5080 \mathrm{G}>\mathrm{T}$ & NS & $1(1)$ & 12 & $\mathrm{R}$ \\
\hline 18 & c.5102_5103delTG & FS & $1(0)$ & 3 & $\mathrm{R}$ \\
\hline 22 & c. $5339 \overline{\mathrm{T}}>\mathrm{C}^{\mathrm{c}}$ & MS & $5(2)$ & 1 & NR \\
\hline 23 & c. $5444 \mathrm{G}>\mathrm{A}$ & NS & $2(1)$ & 4 & $\mathrm{R}$ \\
\hline 23 & c. $5445 \mathrm{G}>\mathrm{A}$ & NS & $3(3)$ & 0 & $\mathrm{R}$ \\
\hline 24 & c.5470_5477delATTGGGCA & FS & $1(1)$ & 2 & $\mathrm{R}$ \\
\hline 24 & c.5496_5506delGGTGACCCGAGinsA & FS & $4(4)$ & 3 & $\mathrm{R}$ \\
\hline IVS5 & c. $212+1 \mathrm{G}>\mathrm{A}$ & $\mathrm{SP}$ & $1(0)$ & 6 & $\mathrm{R}$ \\
\hline IVS6 & c. $302-2 \mathrm{~A}>\mathrm{C}$ & SP & $1(1)$ & 1 & $\mathrm{R}$ \\
\hline IVS23 & c. $5467+1 \mathrm{G}>\mathrm{A}$ & SP & $2(0)$ & 5 & $\mathrm{R}$ \\
\hline \multicolumn{6}{|c|}{$B R C A 2$ (16 districts) } \\
\hline 3 & c.276insA & FS & $1(1)$ & 1 & $\mathrm{R}$ \\
\hline 10 & c. $1111 \mathrm{~A}>\mathrm{T}$ & NS & $1(1)$ & 0 & NR \\
\hline 10 & c. $1399 \mathrm{~A}>\mathrm{T}$ & NS & $4(1)$ & 2 & $\mathrm{R}$ \\
\hline 11 & c.2259delT & FS & $1(1)$ & 0 & $\mathrm{R}$ \\
\hline 11 & c.2798_2799delCA & FS & $1(1)$ & 1 & $\mathrm{R}$ \\
\hline 11 & c.3599_3600delGT & FS & $1(0)$ & 6 & $\mathrm{R}$ \\
\hline 11 & c.3744_3747delTGAG & FS & $1(0)$ & 8 & $\mathrm{R}$ \\
\hline
\end{tabular}

(Continued to the next page) 
Table 3. Continued

\begin{tabular}{|c|c|c|c|c|c|}
\hline Site & Mutation $^{\mathrm{a})}$ & Type & $\begin{array}{l}\text { No. of citations } \\
\text { in } \mathrm{KoOC}^{\mathrm{b})}\end{array}$ & $\begin{array}{l}\text { No. of citations } \\
\text { in BIC }\end{array}$ & $\begin{array}{l}\text { No. of citations } \\
\text { in KOHBRA }\end{array}$ \\
\hline 11 & c.4207dupA & FS & $1(1)$ & 0 & NR \\
\hline 11 & c.5576_5579delTTAA & FS & $3(1)$ & 29 & $\mathrm{R}$ \\
\hline 11 & c. $5656 \mathrm{C}>\mathrm{T}$ & NS & $1(1)$ & 2 & $\mathrm{R}$ \\
\hline 13 & c. $6952 \mathrm{C}>\mathrm{T}$ & NS & $1(1)$ & 5 & $\mathrm{R}$ \\
\hline 15 & c. $7480 \mathrm{C}>\mathrm{T}$ & NS & $4(0)$ & 11 & $\mathrm{R}$ \\
\hline 19 & c.8437_8439delGGA & IF & $1(0)$ & 0 & NR \\
\hline 20 & c.8572delC & FS & $1(1)$ & 0 & NR \\
\hline 21 & c.8717_8718delAA & FS & $1(0)$ & 0 & $\mathrm{R}$ \\
\hline 25 & c.9431delC & FS & $1(1)$ & 0 & $\mathrm{R}$ \\
\hline
\end{tabular}

BIC, Breast Cancer Information Core; KOHBRA, Korean Hereditary Breast Cancer; NR, not reported; R, reported; MS, missense; NS, nonsense; FS, frameshift; SP, splicing. ${ }^{a}$ Nomenclature system of the Human Genome Variation Society (http://

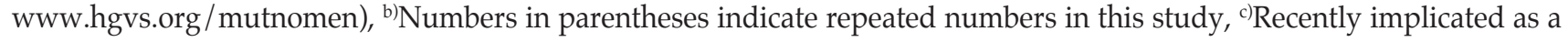
deleterious mutation rather than a variant of unknown significance.

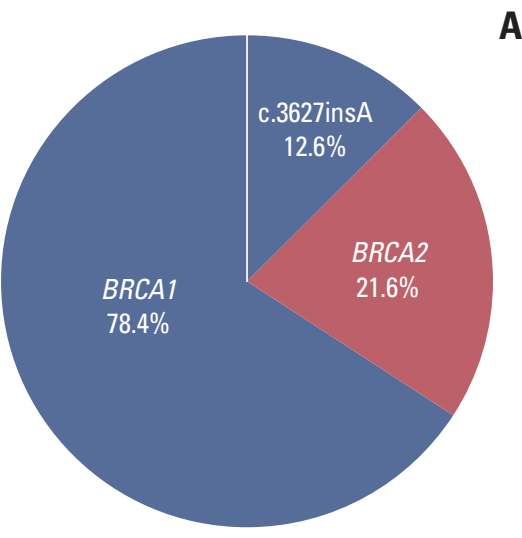

A

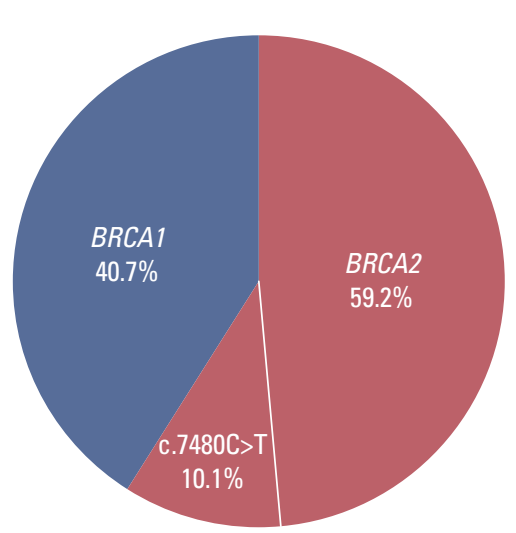

B
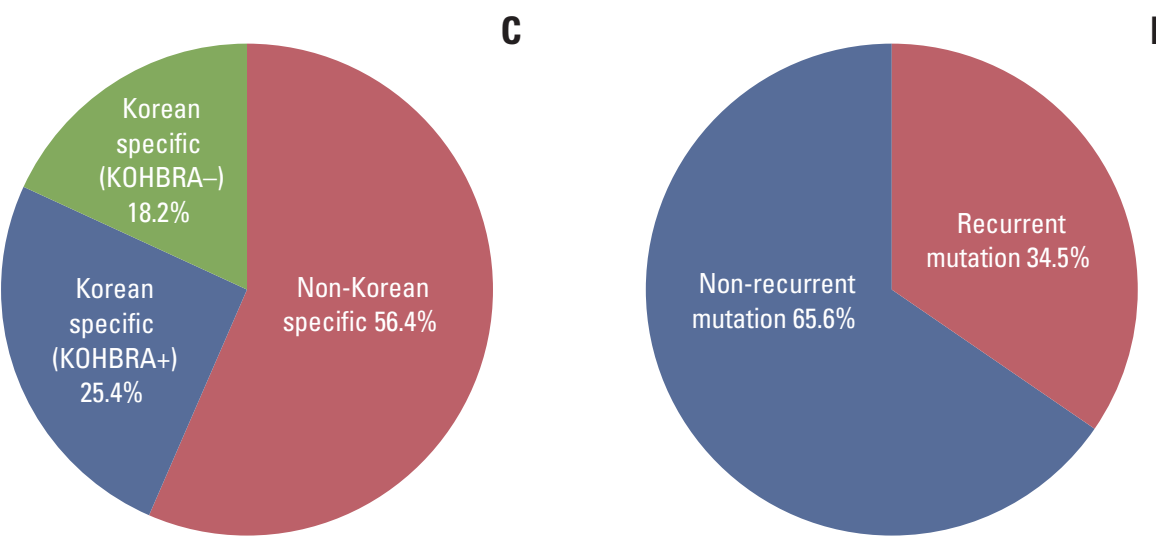

Fig. 2. Spectrum analysis of 111 (55 distinct) $B R C A 1 / 2$ mutations detected in Korean ovarian cancer (KoOC) patients. The ratio of $B R C A 1$ to $B R C A 2$ mutations and most frequent mutation in $\mathrm{KoOC}$ patients $(\mathrm{A})$, and the corresponding values in in Korean breast cancer patients as analyzed in the Korean Hereditary Breast Cancer (KOHBRA) study (B). The proportions of Korean population-specific mutation to non-Korean population-specific mutation (C) and recurrent mutation to non-recurrent mutation (D). 
Table 4. Spectrum of highly frequent $B R C A 1 / 2$ mutations in Korean hereditary breast and ovarian cancer patients

\begin{tabular}{llllrr} 
Gene & Site & \multicolumn{1}{c}{ Mutation ${ }^{\text {a) }}$} & Type & $\begin{array}{c}\text { No. of citations } \\
\text { in KoOC (\%) }\end{array}$ & $\begin{array}{c}\text { No. of citations } \\
\text { in KOHBRA (\%) }\end{array}$ \\
BRCA1 & 11 & c.3627insA & FS & $14(12.6)$ & $9(2.3)$ \\
BRCA1 & 7 & c.390C $>$ A & NS & $8(7.2)$ & $21(5.5)$ \\
BRCA1 & 11 & c.922_924AGCinsT & NS & $5(4.5)$ & $13(3.4)$ \\
BRCA1 & 22 & c.5339T>C ${ }^{\text {b) }}$ & MS & $5(4.5)$ & 0 \\
BRCA1 & 11 & c.3442delG & FS & $5(4.5)$ & $2(0.5)$ \\
\hline
\end{tabular}

KoOC, Korean ovarian cancer; KOHBRA, Korean Hereditary Breast Cancer; FS, frameshift; NS, nonsense; MS, missense. a) Nomenclature system of the Human Genome Variation Society (http://www.hgvs.org/mutnomen), b) Recently implicated as a deleterious mutation rather than a variant of unknown significance.

Table 3. To date, 111 mutations have been reported in KoOC patients, including 87 BRCA1 mutations (78.4\%) and 24 BRCA2 mutations (21.6\%) (Fig. 2A). BRCA1 mutations were more prevalent than $B R C A 2$ mutations, with a $B R C A 1$-to$B R C A 2$ prevalence ratio of 3.6:1. Of the 111 BRCA1/2 mutations, 55 distinct mutations were identified, including 39 $B R C A 1$ and 16 BRCA2 mutations. Among these pathologic 55 mutations, $24(43.6 \%)$ were specific to Korean women and have not been previously reported in the BIC database (Fig. 2C). Ten Korean population-specific mutations (18.2\%) have not yet been reported in the KOHBRA study. Nineteen distinct mutations (19/55 distinct, 34.5\%) were recurrent and were detected in at least two unrelated patients (Fig. 2D). Of these recurrent mutations, five were highly recurrent and were found more than five times in unrelated patients: c.3627insA ( $n=14)$, c.390C $>$ A $(n=8)$, c.922_923AGCinsT $(n=5)$, c.5339T $>C(n=5)$, and c.3442delG $(n=5)$ (Table 4$)$. These five recurrent mutations account for $33.3 \%$ (37 of 111) of the mutations detected in the Korean population. These highly recurrent mutations were considered to be most likely the founder mutations in $\mathrm{KoOC}$, and all of these have been reported in the KOHBRA study (Table 4).

\section{Discussion}

In this study, we included 279 unselected EOC patients and comprehensively evaluated $B R C A 1 / 2$ mutations in the largest multicenter Korean cohort to date. We also analyzed the $B R C A 1 / 2$ mutation spectrum, including all mutation variants previously reported in KoOC. Across previous studies in Korea, the frequency of $B R C A 1 / 2$ mutations has reportedly been quite diverse, ranging between $23.8 \%$ and $31.9 \%$ [9-11] (S3 Table); this variation could have been caused by interstudy heterogeneity, including the differences in sample size, inclusion criteria, and the methods used for detecting mutation. In the present study, the overall frequency of BRCA1/2 mutations in unselected KoOC patients was 16.5\% (Fig. 1A), which was comparable to the frequency of $13 \%$ to $15 \%$ in western cohorts $[6,14,15]$. In addition, the frequency of $B R C A 1 / 2$ mutations observed in the present study was comparable to the frequencies reported in other recent Asian reports, ranging from $11 \%$ to $17 \%$ [16-18]. These data suggest that there are no marked ethnic differences in the frequency of $B R C A 1 / 2$ mutations.

In terms of the age-of-onset, patients with $B R C A 1 / 2$ mutation are characterized by developing EOC at a younger age, based on a report of western cohorts [6]. Unlike the data for western cohorts, in this study, the mean age of patients with $B R C A 1 / 2$ mutation was not significantly lower than that of those without $B R C A 1 / 2$ mutation $(53.7 \pm 9.6$ years vs. $54.2 \pm 10.9$ years, $\mathrm{p}=0.765$ ). There were no significant differences in the proportion of patients with early age-of-onset $(<50$ years) of ovarian cancer between $B R C A 1 / 2$ mutation carriers and noncarriers $(39.1 \%$ vs. $30.5 \%, \mathrm{p}=0.223)$ in KoOC patients. Similarly to the present study, other studies including Asian populations have also shown no significant difference in the mean age-of-onset based on the presence or absence of $B R C A 1 / 2$ mutation [16-18]. Difference of genetic background and non-genetic factors, such as birth cohort and reproductive and lifestyle-related factors, could have influenced different results in Asian EOC patients.

Regarding the clinicopathological findings, patients with $B R C A 1 / 2$ mutations are characterized by serous histology $[6,19]$ and advanced stage with unfavorable outcomes $[6,19,20]$. In the present study, 91.3\% (42/46 BRCA1/2 mutation cases) had serous histology (Table 1). Only four cases $(8.7 \%)$ with non-serous histology were identified, comprising three cases with clear carcinoma and one with endometrioid carcinoma. We did not find any other mucinous or mixed types (S2 Table). The fraction of serous carcinoma in KoOC patients with $B R C A 1 / 2$ mutation was comparable to those 
Table 5. Comparison of $B R C A 1 / 2$ mutations in unselected patients with ovarian cancer from three Asian countries

\begin{tabular}{lccc} 
Characteristic & $\begin{array}{c}\text { Japan } \\
\text { Sakamoto et al. [17] }\end{array}$ & $\begin{array}{c}\text { China } \\
\text { Shi et al. [18] }\end{array}$ & $\begin{array}{c}\text { Korea } \\
\text { This study }\end{array}$ \\
\hline Total No. & 95 & 916 & 278 \\
Overall prevalence of BRCA1/2 mutations & $12(12.6)$ & $153(16.7)$ & $46(16.5)$ \\
\hline Prevalence of BRCA1/2 mutations with FHBOC & $6 / 36(16.7)$ & $39 / 84(46.4)$ & $19 / 58(32.8)$ \\
Ratio of $B R C A 1: B R C A 2$ mutations (n:n) & $1: 1.4(5: 7)$ & $3.3: 1(120: 36)$ & $3.2: 1(35: 11)$ \\
\hline Age-of-onset, mean (yr) & 57 & & \\
$\quad$ BRCA1/2 mutation+ & 55 & 53 & 53 \\
$\quad$ BRCA1/2 mutation- & $12 / 12(100)$ & $131 / 153(85.6)$ & $42 / 46(91.3)$ \\
Serous histology & $12 / 12(100)$ & $\left.91 / 97^{b}\right)(93.8)$ & $40 / 46(87.0)$ \\
\hline Advanced FIGO stage (III/IV)
\end{tabular}

Values are presented as number (\%). FHBOC, family history of breast/ovarian cancer; FIGO, International Federation of

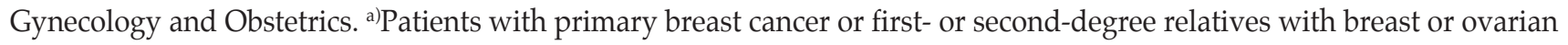
cancer, ${ }^{b}$ Cases with unknown stage $(n=56)$ were excluded.

previously mentioned in some western reports. Our study also found that $B R C A 1 / 2$ mutations were significantly associated with an advanced FIGO stage of III/IV $(\mathrm{p}=0.007)$ and LN metastasis ( $\mathrm{p}=0.011$ ) (Table 1 ); in case of LN metastasis, it was not significant in multivariate logistic regression (Table 2).

Recently, two relatively large population-based studies including 95 and 916 women with unselected ovarian cancer were performed in Japan [17] and China [18], respectively, which are geographically close to Korea. On comparing three studies of East Asian populations, including the present Korean study, we found no marked ethnic differences in the BRCA1/2 mutation frequency among the studies (12.6\% in Japan, $16.7 \%$ in China, and 16.5\% in Korea) (Table 5). These East Asian studies showed no significant difference in the mean age-of-onset between BRCA1/2 mutation carriers and non-carriers (Japan, 57 years vs. 55 years; China, 53 years vs. 54 years; and Korea, 53 years vs. 54 years) (Table 5). In addition, these three studies revealed significant associations between BRCA1/2 mutation and clinicopathological characteristics, including serous histology and advanced FIGO stage (Table 5). However, compared with EOC patients with $B R C A 1 / 2$ mutation in Korea and China, those in Japan showed a lower frequency of $B R C A 1 / 2$ mutation and higher mean age of onset. The high frequency of BRCA2 mutations and the low proportion of $\mathrm{FH}$ of ovarian and/or breast cancer in Japanese EOC patients may have led to these differences in results, possibly indicating that the BRCA1/2 mutation spectrum and/or founder mutations in Japanese EOC patients markedly differ from those in the other two countries.

Although only a few single-center studies including KoOC patients have been done, a large majority of spectrum analy- sis of $B R C A 1 / 2$ mutations in Korean HBOC patients was performed by the nationwide KOHBRA study [12,13]. Among the 2,403 index patients, 378 were found to carry BRCA1/2 mutations. Overall, 153 distinct mutations were identified, including 63 in BRCA1 and 90 in BRCA2. When the BRCA1/2 mutation spectrum was compared between KoOC and KoBC patients, the BRCA1-to-BRCA2 ratio was 3.6:1.0 in KoOC and 1.0:1.4 in KoBC patients, representing that $B R C A 1$ mutations $(78.4 \%)$ were predominant in $\mathrm{KoOC}$ (Fig. 2A), whereas BRCA2 mutations $(59.2 \%)$ were predominant in $\mathrm{KoBC}$ (Fig. 2B). In the KOHBRA study, a replacement mutation, c.7480C $>\mathrm{T}$, in the BRCA2 gene, which was identified as a Korean founder mutation through haplotype analysis by Seong et al. [21], was the most commonly detected mutation, accounting for $10.1 \%$ of all BRCA1/2 mutations (Fig. 2B). In the present study of KoOC patients, c.3627insA in the BRCA1 gene, was the most commonly detected mutation, accounting for $12.6 \%$ of all BRCA1/2 mutations (Fig. 2A), and c.7480C> $\mathrm{T}$ was identified in only four unrelated EOC patients, accounting for $3.6 \%$ of all $B R C A 1 / 2$ mutations (Table 3 ). In our study, the BRCA1/2 mutation spectrum varied according to the cancer type (ovarian and breast cancers) among the Korean HBOC population. The inconsistency of the BRCA1/2 mutation spectrum between ovarian cancer and breast cancer in Korean HBOC was an unexpected result. Previously, Rebbeck et al. [22] investigated hazard ratios for breast and ovarian cancer based on mutation type, function, and nucleotide position in the international sample comprised of 19,581 BRCA1/2 mutation carriers from 55 centers in 33 countries on six continents. They identified three breast cancer cluster regions (BCCRs) and one ovarian cancer cluster region (OCCR) in BRCA1 and three BCCRs and three OCCRs in BRCA2, suggesting that breast and ovarian cancer risks were different 
by type and location of $B R C A 1 / 2$ mutations. These results support possible presence of mutation sequence-associated penetrance tendency according to cancer type, breast or ovarian cancer, in hereditary KoBOC. To elucidate the likelihood of mutation sequence-related penetrance tendency leading to breast or ovarian cancer in Korean HBOC, further studies regarding pooled database and risk assessment of BRCA1/2 mutations for Korean HBOC are required.

The identification of recurrent mutations, including founder mutations, enables the development of cost-effective screening protocols and more efficient genetic counseling. In previous studies including Jewish populations [23-25], three mutations (BRCA1 c.68_69delAG, c.5266dupC, and BRCA2 c.5946delT) were identified as highly recurrent founder mutations, accounting for approximately $90 \%$ of all BRCA1/2 mutations. In fact, screening based on these three founder mutations alone is currently ongoing in clinical practice for Ashkenazi Jewish individuals. In the present study, 65.4\% (36 of 55 distinct) of BRCA1/2 mutations were non-recurrent and the remaining $34.6 \%$ (19 of 55 distinct) were recurrent. Among the recurrent $B R C A 1 / 2$ mutations, five highly recurrent mutations, which were the candidates for Korean founder mutations, accounted for only 33.3\% (37 of 111) of mutations detected in KoOC (Table 4). Considering the diversity of mutation spectrum and the low proportion of highly recurrent mutations in $\mathrm{KoOC}$ patients with $B R C A 1 / 2$ mutation, a screening protocol aimed at identifying highly recurrent founder mutations may not be effective. Currently, a full direct sequencing analysis for $B R C A 1 / 2$ is being performed in KoOC patients for the initial screening of HBOC.

Although this study is the first multi-center study in Korea, all the participating centers are located in the city of Busan, making our study less representative of the country as a whole. In addition, the absolute number of participants carrying $B R C A 1 / 2$ mutations was relatively small. Nevertheless, the prevalence and clinical significance, excluding the early onset of ovarian cancer, of BRCA1/2 mutations in KoOC patients was not significantly different from the values reported in large population-based western studies. In this investigation, we found that $\mathrm{KoOC}$ and $\mathrm{KoBC}$ had different spectra of the $B R C A 1 / 2$ mutations; however, indirect analyses between KoOC and $\mathrm{KoBC}$ patients were conducted to compare the $B R C A 1 / 2$ mutation spectrum; herein, the data for KoBC patients were from the KOHBRA study. To confirm our results, further direct comparisons of $B R C A 1 / 2$ mutation spectra in a single cohort of Korean HBOC patients is required.

In conclusion, we demonstrated herein that KoOC patients with BRCA1/2 mutation were significantly associated with several clinicopathologic factors, such as serous histology and an advanced FIGO stage. However, KoOC patients with $B R C A 1 / 2$ mutation were not characterized by an early ageof-onset (age $<50$ ) of ovarian cancer. An analysis of the $B R C A 1 / 2$ mutation spectrum in KoOC patients showed that the $B R C A 1$-to- $B R C A 2$ ratio and the most commonly detected mutation were different from those of KoBC patients. Owing to the different mutation spectra of KoOC and KoOC patients among Korean HBOC, there were might be presence of possible penetrance tendency leading to breast cancer or ovarian cancer by mutation sequence-specific manner. Taken together, our observations may provide an insight for better genetic counseling and clinical surveillance for the at-risk relatives of KoOC patients.

\section{Electronic Supplementary Material}

Supplementary materials are available at Cancer Research and Treatment website (https: // www.e-crt.org).

\section{Conflicts of Interest}

Conflict of interest relevant to this article was not reported.

\section{Acknowledgments}

This research was supported in part by a Biomedical Research Institute Grant (2017-01), Pusan National University Hospital and the Bio \& Medical Technology Development Program of the NRF funded by the Korean government, MSIP (2016M3A9E8942067).

\section{References}

1. Banerjee S, Kaye SB. New strategies in the treatment of ovarian cancer: current clinical perspectives and future potential. Clin Cancer Res. 2013;19:961-8.

2. Kim SI, Lim MC, Lim J, Won YJ, Seo SS, Kang S, et al. Incidence of epithelial ovarian cancer according to histologic subtypes in Korea, 1999 to 2012. J Gynecol Oncol. 2016;27:e5.
3. Jung KW, Won YJ, Oh CM, Kong HJ, Lee DH, Lee KH, et al. Cancer statistics in Korea: incidence, mortality, survival, and prevalence in 2014. Cancer Res Treat. 2017;49:292-305.

4. Lakhani SR, Manek S, Penault-Llorca F, Flanagan A, Arnout L, Merrett S, et al. Pathology of ovarian cancers in BRCA1 and BRCA2 carriers. Clin Cancer Res. 2004;10:2473-81. 
5. Tan DS, Rothermundt C, Thomas K, Bancroft E, Eeles R, Shanley $\mathrm{S}$, et al. "BRCAness" syndrome in ovarian cancer: a casecontrol study describing the clinical features and outcome of patients with epithelial ovarian cancer associated with BRCA1 and BRCA2 mutations. J Clin Oncol. 2008;26:5530-6.

6. Alsop K, Fereday S, Meldrum C, deFazio A, Emmanuel C, George J, et al. BRCA mutation frequency and patterns of treatment response in BRCA mutation-positive women with ovarian cancer: a report from the Australian Ovarian Cancer Study Group. J Clin Oncol. 2012;30:2654-63.

7. Fong PC, Yap TA, Boss DS, Carden CP, Mergui-Roelvink M, Gourley $\mathrm{C}$, et al. Poly(ADP)-ribose polymerase inhibition: frequent durable responses in BRCA carrier ovarian cancer correlating with platinum-free interval. J Clin Oncol. 2010;28: 2512-9.

8. Audeh MW, Carmichael J, Penson RT, Friedlander M, Powell B, Bell-McGuinn KM, et al. Oral poly(ADP-ribose) polymerase inhibitor olaparib in patients with BRCA1 or BRCA2 mutations and recurrent ovarian cancer: a proof-of-concept trial. Lancet. 2010;376:245-51.

9. Lim MC, Kang S, Seo SS, Kong SY, Lee BY, Lee SK, et al. BRCA1 and BRCA2 germline mutations in Korean ovarian cancer patients. J Cancer Res Clin Oncol. 2009;135:1593-9.

10. Choi MC, Heo JH, Jang JH, Jung SG, Park H, Joo WD, et al. Germline mutations of BRCA1 and BRCA2 in Korean ovarian cancer patients: finding founder mutations. Int J Gynecol Cancer. 2015;25:1386-91.

11. Eoh KJ, Park HS, Park JS, Lee ST, Han J, Lee JY, et al. Comparison of clinical outcomes of BRCA1/2 pathologic mutation, variants of unknown significance, or wild type epithelial ovarian cancer patients. Cancer Res Treat. 2017;49:408-15.

12. Kim H, Cho DY, Choi DH, Choi SY, Shin I, Park W, et al. Characteristics and spectrum of BRCA1 and BRCA2 mutations in 3,922 Korean patients with breast and ovarian cancer. Breast Cancer Res Treat. 2012;134:1315-26.

13. Kang E, Seong MW, Park SK, Lee JW, Lee J, Kim LS, et al. The prevalence and spectrum of BRCA1 and BRCA2 mutations in Korean population: recent update of the Korean Hereditary Breast Cancer (KOHBRA) study. Breast Cancer Res Treat. 2015;151:157-68.

14. Pal T, Permuth-Wey J, Betts JA, Krischer JP, Fiorica J, Arango $\mathrm{H}$, et al. BRCA1 and BRCA2 mutations account for a large proportion of ovarian carcinoma cases. Cancer. 2005;104:2807-16.

15. Risch HA, McLaughlin JR, Cole DE, Rosen B, Bradley L, Fan
I, et al. Population BRCA1 and BRCA2 mutation frequencies and cancer penetrances: a kin-cohort study in Ontario, Canada. J Natl Cancer Inst. 2006;98:1694-706.

16. Hasmad HN, Lai KN, Wen WX, Park DJ, Nguyen-Dumont T, Kang PC, et al. Evaluation of germline BRCA1 and BRCA2 mutations in a multi-ethnic Asian cohort of ovarian cancer patients. Gynecol Oncol. 2016;141:318-22.

17. Sakamoto I, Hirotsu Y, Nakagomi H, Ouchi H, Ikegami A, Teramoto $\mathrm{K}$, et al. BRCA1 and BRCA2 mutations in Japanese patients with ovarian, fallopian tube, and primary peritoneal cancer. Cancer. 2016;122:84-90.

18. Shi T, Wang P, Xie C, Yin S, Shi D, Wei C, et al. BRCA1 and BRCA2 mutations in ovarian cancer patients from China: ethnic-related mutations in BRCA1 associated with an increased risk of ovarian cancer. Int J Cancer. 2017;140:2051-9.

19. Boyd J, Sonoda Y, Federici MG, Bogomolniy F, Rhei E, Maresco DL, et al. Clinicopathologic features of BRCA-linked and sporadic ovarian cancer. JAMA. 2000;283:2260-5.

20. Soegaard M, Kjaer SK, Cox M, Wozniak E, Hogdall E, Hogdall $\mathrm{C}$, et al. BRCA1 and BRCA2 mutation prevalence and clinical characteristics of a population-based series of ovarian cancer cases from Denmark. Clin Cancer Res. 2008;14:3761-7.

21. Seong MW, Cho S, Noh DY, Han W, Kim SW, Park CM, et al. Comprehensive mutational analysis of BRCA1/BRCA2 for Korean breast cancer patients: evidence of a founder mutation. Clin Genet. 2009;76:152-60.

22. Rebbeck TR, Mitra N, Wan F, Sinilnikova OM, Healey S, McGuffog L, et al. Association of type and location of BRCA1 and BRCA2 mutations with risk of breast and ovarian cancer. JAMA. 2015;313:1347-61.

23. Friedman LS, Szabo CI, Ostermeyer EA, Dowd P, Butler L, Park T, et al. Novel inherited mutations and variable expressivity of BRCA1 alleles, including the founder mutation 185delAG in Ashkenazi Jewish families. Am J Hum Genet. 1995;57:1284-97.

24. Tonin P, Weber B, Offit K, Couch F, Rebbeck TR, Neuhausen $\mathrm{S}$, et al. Frequency of recurrent BRCA1 and BRCA2 mutations in Ashkenazi Jewish breast cancer families. Nat Med. 1996;2: 1179-83.

25. Neuhausen S, Gilewski T, Norton L, Tran T, McGuire P, Swensen J, et al. Recurrent BRCA2 6174delT mutations in Ashkenazi Jewish women affected by breast cancer. Nat Genet. 1996;13:126-8. 